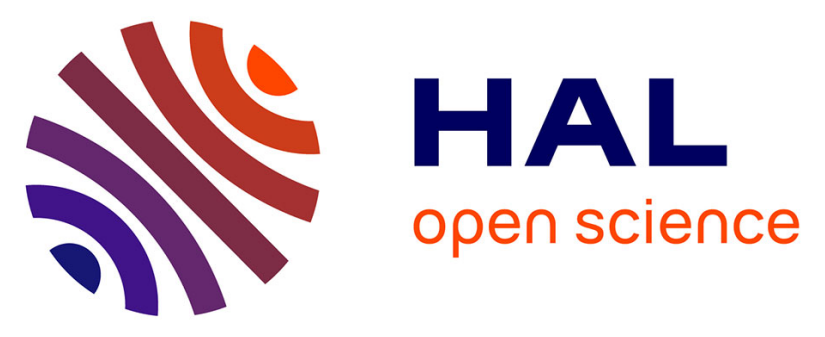

\title{
Development of an on-line solid phase extraction ultra performance liquid chromatography technique coupled to tandem mass spectrometry for quantification of bisphenol $\mathrm{S}$ and bisphenol $\mathrm{S}$ glucuronide: applicability to toxicokinetic investigations
}

Flore C. Grandin, Nicole Picard-Hagen, Véronique V. Gayrard-Troy, Sylvie Puel, Catherine Viguié, Pierre-Louis Toutain, Laurent Debrauwer, Marlène Z. Lacroix

\section{To cite this version:}

Flore C. Grandin, Nicole Picard-Hagen, Véronique V. Gayrard-Troy, Sylvie Puel, Catherine Viguié, et al.. Development of an on-line solid phase extraction ultra performance liquid chromatography technique coupled to tandem mass spectrometry for quantification of bisphenol $\mathrm{S}$ and bisphenol $\mathrm{S}$ glucuronide: applicability to toxicokinetic investigations. Journal of Chromatography A, 2017, 1526, pp.39-46. 10.1016/j.chroma.2017.10.020 . hal-02624905

\section{HAL Id: hal-02624905 \\ https://hal.inrae.fr/hal-02624905}

Submitted on 26 May 2020

HAL is a multi-disciplinary open access archive for the deposit and dissemination of scientific research documents, whether they are published or not. The documents may come from teaching and research institutions in France or abroad, or from public or private research centers.
L'archive ouverte pluridisciplinaire HAL, est destinée au dépôt et à la diffusion de documents scientifiques de niveau recherche, publiés ou non, émanant des établissements d'enseignement et de recherche français ou étrangers, des laboratoires publics ou privés. 


\section{Accepted Manuscript}

Title: Development of an on-line Solid Phase Extraction Ultra Performance Liquid Chromatography technique coupled to tandem Mass Spectrometry for quantification of Bisphenol S and Bisphenol S Glucuronide: applicability to toxicokinetic investigations

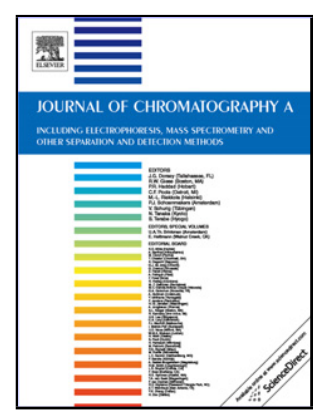

Authors: Flore Grandin, Nicole Picard-Hagen, Véronique

Gayrard, Sylvie Puel, Catherine Viguié, Pierre-Louis Toutain, Laurent Debrauwer, Marlène Z. Lacroix

PII: $\quad$ S0021-9673(17)31504-2

DOI: $\quad$ https://doi.org/10.1016/j.chroma.2017.10.020

Reference: $\quad$ CHROMA 358925

To appear in: $\quad$ Journal of Chromatography A

Received date: $\quad 20-4-2017$

Revised date: $\quad 8-8-2017$

Accepted date: $\quad$ 6-10-2017

Please cite this article as: Flore Grandin, Nicole Picard-Hagen, Véronique Gayrard, Sylvie Puel, Catherine Viguié, Pierre-Louis Toutain, Laurent Debrauwer, Marlène Z.Lacroix, Development of an on-line Solid Phase Extraction Ultra Performance Liquid Chromatography technique coupled to tandem Mass Spectrometry for quantification of Bisphenol S and Bisphenol S Glucuronide: applicability to toxicokinetic investigations, Journal of Chromatography A https://doi.org/10.1016/j.chroma.2017.10.020

This is a PDF file of an unedited manuscript that has been accepted for publication. As a service to our customers we are providing this early version of the manuscript. The manuscript will undergo copyediting, typesetting, and review of the resulting proof before it is published in its final form. Please note that during the production process errors may be discovered which could affect the content, and all legal disclaimers that apply to the journal pertain. 
Development of an on-line Solid Phase Extraction Ultra Performance Liquid Chromatography technique coupled to tandem Mass Spectrometry for quantification of Bisphenol $\mathrm{S}$ and Bisphenol S Glucuronide: applicability to toxicokinetic investigations.

Flore Grandin ${ }^{\mathrm{a}}$, Nicole Picard-Hagen ${ }^{\mathrm{a}}$, Véronique Gayrard ${ }^{\mathrm{a}}$, Sylvie Puel ${ }^{\mathrm{a}}$, Catherine Viguiéa Pierre-Louis Toutain ${ }^{\mathrm{a}}$, Laurent Debrauwer ${ }^{\mathrm{b}}$, and Marlène Z. Lacroix ${ }^{\mathrm{a}^{*}}$

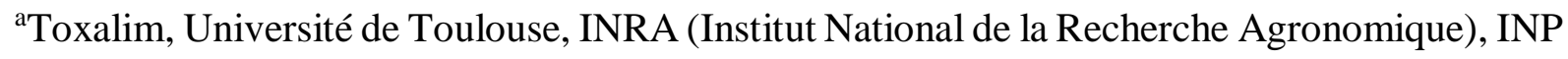
(Institut National Polytechnique de Toulouse) -ENVT (Ecole Nationale Vétérinaire de Toulouse), Toulouse France

' INRA, UMR 1331 Toxalim, Research Centre in Food Toxicology, Axiom Platform, 180 chemin deTournefeuille, 31027 Toulouse cedex, France

Flore Grandin: flore.grandin@inra.fr ; Nicole Picard-Hagen: n.hagen-picard@envt.fr ; Véronique Gayrard: v.gayrard@envt.fr ; Sylvie Puel: sylvie.puel@inra.fr ; Catherine Viguié: c.viguie@envt.fr ; Pierre-Louis Toutain: pl.toutain@envt.fr ; Laurent Debrauwer: laurent.debrauwer@inra.fr; Marlène Z. Lacroix: m.lacroix@envt.fr.

Corresponding author*: Marlène Lacroix, UMR1331 Toxalim, Ecole Nationale Vétérinaire de Toulouse, 23 chemin des Capelles, BP 87614, 31076 Toulouse cedex 3, France, Tel.: 33 (0) 335611939 96, E-mail: m.lacroix@envt.fr

Competing financial interests: The authors declare no conflicts of interest. 


\title{
Highlights
}

- Bisphenol S and Bisphenol S Glucuronide were quantified simultaneously in plasma.

- The method (including sample extraction) enables the assays of 200 samples per day.

- Toxicokinetic parameters of Bisphenol S and its main metabolite were estimated.

- In sheep model, the capacity to eliminate Bisphenol S is less than for Bisphenol A.

\begin{abstract}
Regulatory measures and public concerns regarding bisphenol A (BPA) have led to its replacement by structural analogs, such as Bisphenol S (BPS), in consumer products. At present, no toxicokinetic investigations have been conducted to assess the factors determining human internal exposure to BPS for subsequent risk assessment. Toxicokinetic studies require reliable analytical methods to measure the plasma concentrations of BPS and its main conjugated metabolite, BPS-glucuronide (BPS-G).
\end{abstract}

An efficient on-line SPE-UPLC-MS/MS method for the simultaneous quantification of BPS and BPS-G in ovine plasma was therefore developed and validated in accordance with the European Medicines Agency guidelines for bioanalytical method validation. This method has a limit of quantification of $3 \mathrm{ng} \mathrm{mL}^{-1}$ for BPS and $10 \mathrm{ng} \mathrm{mL}^{-1}$ for BPS-G, an analytical capacity of 200 samples per day, and is particularly well suited to toxicokinetic studies.

Use of this method in toxicokinetic studies in sheep showed that BPS, like BPA, is efficiently metabolized into its glucuronide form. However, the clearances and distributions of BPS and BPS-G were lower than those of the corresponding unconjugated and glucuroconjugated forms of BPA. 
Keywords: Bisphenol S, Bisphenol S glucuronide, Toxicokinetic, Liquid Chromatography, Mass spectrometry. 


\section{Introduction}

Owing to regulatory actions and serious concerns regarding widespread human exposure to Bisphenol A (BPA) and its adverse effects on human health, BPA is gradually being replaced by other bisphenol analogues in many consumer products [1,2]. Bisphenol S (BPS) is commonly used as an alternative to BPA in the production of polycarbonate plastics and epoxy resins for various industrial applications [1]. Despite its high thermal stability, BPS can be found in canned foodstuffs, thermal paper and personal care products [3-8].

Humans are exposed to BPS by the same routes as described for BPA, including dietary exposure [3-6,9], inhalation of indoor dust [10], and transcutaneous route [7,8,11]. In humans, BPS is mainly metabolized in the liver into bisphenol S glucuronide (BPS-G) and eliminated in urine [12,13]. Different studies suggest that BPS exposure may be increasing because of BPA prohibition in some countries [14]. The estimated median daily dietary intake of BPS is 9.55 ng kg-1 bw (body weight) per day [9] and biomonitoring studies recently conducted in several countries found that BPS was detected in $81 \%$ of 315 urine samples, at a geometric mean concentration of $0.168 \mathrm{ng} \mathrm{mL}^{-1}[15,16]$.

Due to its structural similarity with BPA and its widespread use, concern about the safety of BPS has become an important issue $[14,16]$. Indeed, BPS has a similar toxicity profile to BPA [17] but, compared with the numerous studies of BPA, toxicological investigations of BPS remain limited. Understanding the factors which determine maternal internal exposure to BPS constitutes a critical initial step in assessing the health risk of BPS and will require accurate estimation of the toxicokinetic (TK) parameters characterizing the disposition of BPS and BPSG [18]. Development of a reliable method for quantifying BPS and BPS-G over a wide range of concentrations in biological matrices is therefore crucial to estimate the TK parameters with 
a high level of confidence. However, even though an analytical standard of BPS-G is now commercially available, it is too expensive for use in TK studies which require several grams of compound. We have already developed a method for BPA-G purification from ewe urine by using flash chromatography [19], that could be adapted to produce large quantities of BPS-G for TK purposes.

Bisphenols are usually extracted from matrices by solid phase extraction (SPE) and quantified by gas or liquid chromatography coupled with tandem mass spectrometry (GC or LC-MS/MS) [20]. Numerous methods have already been described for BPS assay in environmental matrices such as indoor dust, sludge, water, soil, sediment [10,21,22], consumer products [7] and foodstuffs $[5,6,9,23]$, but few have been developed for biological fluids [24,25]. In these complex matrices, BPS has systematically been measured after enzymatic hydrolysis which provides a measure of total BPS concentrations, i.e.the concentrations of both BPS and its conjugated metabolites. With this kind of method, BPS-G concentrations can only be assayed by subtracting the unconjugated BPS assayed prior to hydrolysis from the total BPS found after hydrolysis. Such a method is not optimal since a large sample volume is required (which is time-consuming), the use of enzyme constitutes a biological source of variability and specificity for BPS-G is lacking as the usual enzymes target not only BPS-G but other BPS conjugates [26]. Consequently, enzymatic hydrolysis is not a suitable method for TK studies.

The main goal of this study was therefore to develop and validate an original method for the simultaneous quantification of BPS and BPS-G in plasma by on-line SPE-LC-MS/MS.The suitability of this method for TK applications was evaluated by simultaneously monitoring BPS and BPS-G in ovine plasma following intravenous BPS and BPS-G administrations.

\section{Materials and methods}

\subsection{Chemicals}


Bisphenol S (BPS), acetonitrile (AcN), propylene glycol (PG), formic acid (FA) and acetic acid (AA) were purchased from Sigma-Aldrich (Saint Quentin Fallavier, France). Ethanol (EtOH) and methanol $(\mathrm{MeOH})$ were purchased from Fischer Scientific (Illkirch-Graffenstaden, France). Water was provided by an ultrapure water system (Elga Labwater Veolia, Anthony, France). The solvents and acids used for flash chromatography were HPLC grade and those used for liquid chromatography were at least LC-MS grade.

Zinc sulfate $\left(\mathrm{ZnSO}_{4}\right)$ was purchased from Prolabo (Paris, France). Bisphenol S d8 (BPSd8), bisphenol S glucuronide (BPS-G, used as analytical standard) and bisphenol S glucuronide d8 (BPS-Gd8) were obtained from Toronto Research Chemicals (TRC, Toronto, Canada).

The same stock solutions of BPS and BPS-G in $\mathrm{H}_{2} \mathrm{O} / \mathrm{AcN}$ were used to prepare separate working solutions in drug-free sheep plasma for standard curve calibrators and quality control (QC) samples. For the standard curve, the first working solution contained BPS and BPS-G at 10 and $100 \mu \mathrm{g} \mathrm{mL}^{-1}$, respectively. This first working solution was then diluted in BPS-free sheep plasma to obtain the second working solution at 100 and $1000 \mathrm{ng} \mathrm{mL}^{-1}$. These working solutions were subsequently diluted in BPS-free sheep plasma to obtain concentrations for the standard curve calibrators ranging from 3 to $5000 \mathrm{ng} \mathrm{mL}^{-1}$ and 10 to $50000 \mathrm{ng} \mathrm{mL}^{-1}$ for BPS and BPS-G, respectively.

QC samples were prepared at concentrations of 9, 250 and $3750 \mathrm{ng} \mathrm{mL} \mathrm{L}^{-1}$ and 30, 2500 and $37500 \mathrm{ng} \mathrm{mL} \mathrm{m}^{-1}$ for BPS and BPS-G, respectively. Calibrators and QC solutions were stored at $-20^{\circ} \mathrm{C}$ in $100 \mu \mathrm{L}$ aliquots.

The working solutions of the internal standards (IS, BPSd8 and BPS-Gd8) were prepared using stock solutions of BPSd8 and BPS-Gd8 in $\mathrm{H}_{2} \mathrm{O} / \mathrm{AcN}$ at $1 \mathrm{mg} \mathrm{mL}^{-1}$ to obtain a solution at $10 \mu \mathrm{g}$ $\mathrm{mL}^{-1}$ for BPSd8 and $100 \mu \mathrm{g} \mathrm{mL}{ }^{-1}$ for BPS-Gd8 in $\mathrm{AcN} / \mathrm{ZnSO}_{4}(50 / 50, \mathrm{v} / \mathrm{v})$, and stored at $-20^{\circ} \mathrm{C}$. A new IS solution was prepared each week by diluting 100-fold the previous working solution 
of BPSd8/BPS-Gd8 in AcN/ZnSO 4 to obtain concentrations of $100 \mathrm{ng} \mathrm{mL}^{-1}$ and $1000 \mathrm{ng} \mathrm{mL}^{-1}$ for BPSd8 and BPS-Gd8, respectively.

\subsection{Animal treatment and sample collection}

All animal procedures were carried out in accordance with accepted standards of humane animal care under agreement number 31-2016-167 from the French Ministry of Agriculture and validated by the ethics committee from the French Ministry of Higher Education and Research (project number: 216-167).

The first experiment was designed to purify a large amount of BPS-G from urine of five ewes that received an oral administration of BPS at the dose of $100 \mathrm{mg} \mathrm{kg}^{-1} \mathrm{bw}$. Total urine was collected and BPS-G was isolated by flash chromatography, then identified and quantified by LC-MS/MS (see supplementary data).

The TK experiment was carried out on four Lacaune ewes with a mean $( \pm \mathrm{SD})$ body weight of $59.6 \pm 13.5 \mathrm{~kg}$. Each ewe received both BPS $\left(5 \mathrm{mg} \mathrm{kg}^{-1} \mathrm{bw}\right)$ and BPS-G $\left(2 \mathrm{mg} \mathrm{kg}^{-1} \mathrm{bw}\right)$ intravenously during two different periods four days apart, according to a cross-over design.

BPS was extemporaneously dissolved in $\mathrm{EtOH} / \mathrm{H}_{2} \mathrm{O} / \mathrm{PG}(10 / 11 / 79, \mathrm{v} / \mathrm{v} / \mathrm{v})$ at $50 \mathrm{mg} \mathrm{mL}^{-1}$. Purified BPS-G was extemporaneously dissolved in $\mathrm{NaCl} 0.9 \%$ at a concentration of $50 \mathrm{mg}$ $\mathrm{mL}^{-1}$. BPS and BPS-G were intravenously administered via an indwelling catheter inserted into the left jugular vein just prior to the administration.

Serial blood samples were collected before and at 2, 4, 8, 15, 20, $30 \mathrm{~min}$ and 1, 1.5, 2, 3, 4, 6, $8,10,15,21,24,34,48$ and $72 \mathrm{~h}$ after administration.

Blood samples were obtained by direct puncture of the right jugular vein. They were collected in heparinized tubes, immediately chilled in ice and centrifuged for $10 \mathrm{~min}$ at $3000 \times \mathrm{g}$ at $4{ }^{\circ} \mathrm{C}$. The supernatant plasma was aliquoted $(100 \mu \mathrm{L})$ and stored at $-20^{\circ} \mathrm{C}$ until assayed. 


\subsection{Instrument and analytical conditions}

\subsubsection{Instrument}

BPS and BPS-G identification and quantification were performed with a 2D Acquity ultra performance liquid chromatography system $\left(2 \mathrm{D}-\mathrm{UPLC}^{\circledR}\right)$ coupled to a Xevo ${ }^{\circledR}$ triple quadrupole mass spectrometer (Waters, Milford, MA, USA). The first UPLC pump was used for sample extraction and the second was used as the analytical pump, both pumps being connected with the autosampler and the mass spectrometer by two 6-port valves integrated in the column heater. Samples were ionized in negative electrospray ionization mode $\left(\mathrm{ESI}^{-}\right)$. The capillary voltage and source temperature were set at $3.1 \mathrm{kV}$ and $150^{\circ} \mathrm{C}$, respectively. The desolvation temperature and nitrogen flow rate were set at $600^{\circ} \mathrm{C}$ and $1000 \mathrm{~L} \mathrm{hr}^{-1}$, respectively. Argon was used as collision gas at a flow rate of $0.15 \mathrm{~mL} \mathrm{~min}^{-1}$.

\subsubsection{Simultaneous quantification of BPS and BPS-G in ovine plasma}

BPS and BPS-G plasma samples $(100 \mu \mathrm{L})$ were extracted from the matrix by adding $100 \mu \mathrm{L}$ of a $\mathrm{ZnSO}_{4} / \mathrm{AcN}$ mixture containing IS, to precipitate the proteins. The mixture was shaken at $10^{\circ} \mathrm{C}$ for 1 minute at $3000 \mathrm{rpm}$ (MB-102, Bioer, Hangzhou, China) and centrifuged for $10 \mathrm{~min}$. The supernatant $(10 \mu \mathrm{L})$ was first concentrated on an XBridge ${ }^{\circledR}$ C8 Direct Connect HP cartridge $(2.1 \mathrm{~mm} \times 30 \mathrm{~mm}, 10 \mu \mathrm{m}$; Waters $)$ at $1 \mathrm{~mL} \mathrm{~min}^{-1}$ flow with $100 \% \mathrm{H}_{2} \mathrm{O}, 0.1 \% \mathrm{FA}$ for $0.7 \mathrm{~min}$ and then eluted on an Acquity CSH C18 column $(2.1 \mathrm{~mm} \times 100 \mathrm{~mm} ; 1.7 \mu \mathrm{m}$; Waters $)$ at $0.35 \mathrm{~mL} \mathrm{~min}^{-1}$ with an $\mathrm{H}_{2} \mathrm{O} / \mathrm{AcN}$ linear gradient $\left(0 \mathrm{~min}, 80 \% \mathrm{H}_{2} \mathrm{O} ; 0.7 \min 80 \% \mathrm{H}_{2} \mathrm{O} ; 3.5\right.$ $\min 40 \% \mathrm{H}_{2} \mathrm{O}$ ). The on-line SPE cartridge and column temperatures were both set at $40^{\circ} \mathrm{C}$. BPS and BPS-G were detected in ESI ${ }^{-}$by multiple reactions monitoring (MRM) mode. MRM transitions of BPS, BPS-G and IS with their respective retention times, cone voltages and collision energies are given in table 1. Chromatographic data were monitored by Masslynx 4.1® software (Waters, Milford, MA, USA). 


\subsection{Validation procedure}

The method was validated according to the European Medicines Agency (EMA) guidelines for bioanalytical method validation [27] in terms of linearity, intra-day and inter-day repeatabilities, sensitivity (low and high) and dilution. Selectivity was tested by comparing six blank plasma chromatograms with chromatograms at the lower limits of quantification (LLOQ). The LLOQs were defined as the lowest concentrations of the calibration curve that could be quantified with less than $20 \%$ precision and within an accuracy range of $80-120 \%$. As blank plasma was systematically contaminated by BPS, a limit of blank (LOB) was estimated by measuring 6 replicates of blank plasma and calculating the mean residual BPS and the standard deviation (SD). For both compounds, the LOD (limit of detection) was first estimated from blank plasma with a signal to noise ratio $(\mathrm{S} / \mathrm{N})$ of 3 and then verified using 6 replicates of plasma samples spiked at the concentration estimated from the blanks $\left(1 \mathrm{ng} \mathrm{mL}^{-1}\right)$. For the BPS and BPS-G calibration curves, both simple $(\mathrm{Y}=\mathrm{aX}+\mathrm{b})$ and quadratic $\left(\mathrm{Y}=\mathrm{aX} \mathrm{X}^{2}+\mathrm{bX}+\mathrm{c}\right)$ models were tested after applying appropriate weighting: $1,1 / \mathrm{X}$ and $1 / \mathrm{X}^{2}(\mathrm{X}=$ nominal concentration). Three approaches were adopted to assess the linearity of the calibration curve: (1) calculation of the relative concentration residuals (RCR\%) between the nominal concentration and the concentration obtained with the model, which should be lower than \pm $15 \%$ (except at the LLOQ, $\pm 20 \%$ ), (2) visual inspection of the residual distribution which should be randomized around the mean and (3) application of a lack of fit test to check the goodness-of-fit of the model. The ULOQ was defined as the highest concentration of the calibration curve that could be quantified without sample dilution. Within-day and betweenday precisions and accuracies of BPS and BPS-G were calculated on three different days and with six replicates of QC samples at three concentration levels (low, middle and high) covering the range of the calibration curve concentrations. Precision and accuracy were calculated for twofold and tenfold dilutions to allow sample quantification above the ULOQ. Recovery was 
evaluated by comparing the analytical response of plasma QC samples obtained after protein precipitation with that of aqueous QC samples diluted in $\mathrm{H}_{2} \mathrm{O} / \mathrm{AcN}(50 / 50)$ for the experiment without on-line SPE. For the on-line SPE recovery assay, the response of extracted QC plasma samples eluted on the on-line SPE was compared with aqueous QC samples diluted in $\mathrm{H}_{2} \mathrm{O} / \mathrm{AcN}$ and eluted without on-line SPE. Matrix effects were assessed by comparing extracted QC plasma samples with extracted aqueous QC samples, and were determined with and without on-line SPE.

\subsection{Toxicokinetic analysis}

Individual plasma concentration-time profiles of BPS and BPS-G were analyzed with a noncompartmental approach using Phoenix ${ }^{\circledR}$ NLME ${ }^{\mathrm{TM}}$ software (version 6.4; Pharsight, Mountain View, CA, USA).

The BPS and BPS-G concentrations were converted into molar concentrations. The area under the plasma concentration-time curve $\left(\mathrm{AUC}_{\text {last }}\right)$ from dosing time to the last sampling time was calculated using the linear-up/log-down rule. The $\mathrm{AUC}$ from $\mathrm{t}=0$ to infinity $\left(\mathrm{AUC}_{\mathrm{inf}}\right)$ was obtained by adding to $\mathrm{AUC}_{\text {last }}$, the area extrapolated from the last observation to infinity by dividing the last observed quantifiable plasma concentration by the slope of the terminal phase as estimated by linear regression, using the best fit option of Phoenix ${ }^{\circledR}$.

The clearance $(\mathrm{Cl})$, mean residence time (MRT), terminal half-life $\left(\mathrm{t}_{1 / 2}\right)$ and steady-state volume of distribution $\left(\mathrm{V}_{\mathrm{ss}}\right)$ of $\mathrm{BPS}$ (BPS-G) were computed with $\mathrm{AUC}_{\mathrm{inf}}$ using classical pharmacokinetic equations [28].

For each ewe, the extent of BPS glucuronoconjugation over the sampling period was first

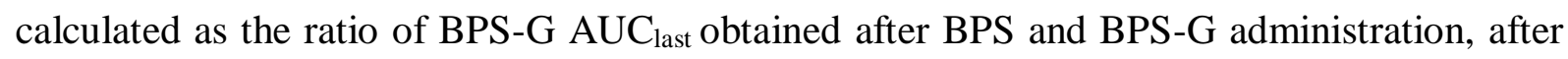
normalizing by the administered molar doses of BPS and BPS-G (equation 1), assuming that the BPS-G clearance was the same after both BPS and BPS-G administration. 
BPS glucuronoconjugation $=\frac{A U C_{\text {last } B P S-G \text { after } B P S \text { iv }}}{A U C_{\text {last } B P S-G \text { after } B P S-G \text { iv }}} \times \frac{\text { Dose }_{B P S-G \text { iv }}}{\text { Dose }_{B P S \text { iv }}}$

(Equation 1)

However, equation 1 indicated that mean BPS glucuronidation was higher than $100 \%$, suggesting that BPS-G clearances varied between the two periods [29]. To take this factor of variation into account, the ratio of the half-lives of BPS-G after BPS and BPS-G administration was incorporated as a surrogate of the clearance in equation 1 to correct the BPS glucuronidation rate in equation 2 [30].

BPS glucuronoconjugation

$$
=\frac{A U C_{\text {last BPS-G after BPS iv }}}{A U C_{\text {last BPS-G after BPS-G iv }}} \times \frac{\text { Dose }_{B P S-G \text { iv }}}{\text { Dose } e_{B P S \text { iv }}} \times \frac{t_{1 / 2 \text { BPS-G after BPS }-G \text { iv }}}{t_{1 / 2 \text { BPS-G after BPS iv }}}
$$

(Equation 2)

\section{Results and discussion}

\subsection{Production of BPS-G from sheep urine}

Considering the large amount of BPS-G required for its use in TK studies and the high cost of this metabolite, BPS-G was produced from sheep urine by adapting a method previously used to purify several grams of BPA-G [19]. Briefly, BPS was administered orally to the sheep to be metabolized to BPS-G and subsequently eliminated in the urines that were collected and purified by flash chromatography. The resulting fractions were identified and quantified by UPLC-MS/MS (see supplementary data). Finally, $2.8 \mathrm{~g}$ of BPS-G was isolated with a purity ranging from 68 to $85 \%$, which is suitable for use in TK studies.

\subsection{Simultaneous quantification of BPS and BPS-G}

A major limitation of bisphenol assays in biological matrices is the potential background contamination from solvents, SPE cartridges, the evaporation process or plastic ware [31], which can lead to erroneous measurements of concentrations when dealing with the $\mathrm{ng} \mathrm{mL}^{-1}$ 
range. For this reason, sample handling and contact with potentially contaminated material were minimized as much as possible by pretreating the plasma samples by simple protein precipitation.

Firstly, BPS and BPS-G were eluted on a C18 BEH column with AcN, as previously described for the simultaneous quantification of BPA and BPA-G [19]. However, despite their similar structures, neither BPS nor BPS-G were correctly eluted and detected under these conditions. Indeed, BPS-G $(\log P=-0.33)$ is much more polar than BPA $(\log P=3.43)$ and BPA-G $(\log P$ $=1.12$ ), and so the resulting supernatant obtained by AcN precipitation was insufficiently polar to correctly elute BPS-G on this C18 column, leading to split peaks (Figure 1). Therefore, a completely new method was developed for simultaneous BPS and BPS-G quantification.

First of all, other precipitant mixtures using a more polar solvent $(\mathrm{MeOH})$, acidified water (TFA) or metallic ions $\left(\mathrm{ZnSO}_{4}\right)$ were tested in different proportions to determine the best elution conditions for both BPS and BPS-G. MeOH precipitation gave the same results as those obtained with $\mathrm{AcN}$ and precipitation under acidic conditions hindered the subsequent negative ionization of BPS and BPS-G. The combined use of $\mathrm{ZnSO}_{4}$ with $\mathrm{AcN}$ made it possible to reduce the volume of organic solvent without disturbing protein precipitation and MS detection. Finally, the best peak symmetry and sensitivity for both compounds was obtained with the $\mathrm{AcN}_{\mathrm{ZnSO}}(1 / 1, \mathrm{v} / \mathrm{v})$ combination. Recovery for BPS was $108 \%$, but very low for BPS-G (2\%) with few matrix effects for BPS (106\%) and considerable ion suppression plus matrix effects for BPS-G (4\%) (Table 2). Under these conditions, BPS-G could be differentiated from the

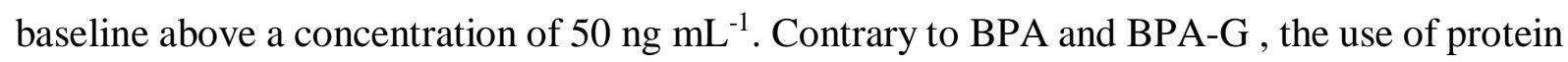
precipitation alone was insufficient to provide good sensitivities and consistent recoveries, particularly for BPS-G.

On-line SPE liquid chromatography is an appropriate extraction process to minimize sample treatment and therefore limit sample contamination, and to maximize analyte recovery $[32,33]$. 
Thus, different SPE cartridges (C8, C18 and polymeric phase) were tested and the washing solvent composition and elution time were optimized to concentrate BPS and BPS-G and obtain consistent recoveries. The best results were obtained by using a C8 cartridge with a loading time of 0.7 min with $100 \%$ of water acidified with $0.1 \%$ formic acid. Although formic acid can reduce negative ionization, its presence considerably improved the peak symmetry of BPS and BPS-G (Figure 2). Extraction efficiency was 31 and 106\% for BPS and BPS-G, respectively with a matrix effect of about $45 \%$ for BPS and $71 \%$ for BPS-G. Oddly, an increase in the matrix effects was observed for BPS when the on-line SPE system was used (Table 2). The preconcentration of BPS and BPS-G generated by the SPE system might also result in simultaneous pre-concentration of the plasma impurities. However, this system does allow the improvement of BPS and BPS-G peak symmetry and significantly enhances BPS-G detection. Indeed, the peak area of BPS-G was 56-fold higher when on-line SPE was used (Table 2).

Different analytical columns and gradients were then tested to see which provided suitable BPS and BPS-G elution within the shortest run time. The best separation was obtained in 4.5 min on a CSH C18 column, with retention times of $3.0 \mathrm{~min}$ and $2.5 \mathrm{~min}$, for BPS and BPS-G, respectively. Two MRM transitions were optimized for each compound, namely 249>92 and 249>108 for BPS (corresponding to the loss of $\mathrm{C}_{6} \mathrm{H}_{5} \mathrm{SO}_{3}$ and $\mathrm{C}_{6} \mathrm{H}_{5} \mathrm{SO}_{2}$ respectively) [34], and 425>249 and 425>108 for BPS-G (loss of the glucuronide moiety and $\mathrm{C}_{6} \mathrm{H}_{5} \mathrm{SO}_{2}$, respectively). The MRM transition yielding the highest signal to noise ratio and the highest intensity was selected for quantification and the second MRM transition was used for confirmation (Table 1).

\subsubsection{Validation of the method}

\subsubsection{Linearity, ULOQ, dilution}

For BPS, calibration curves with concentrations ranging from 3 to $5000 \mathrm{ng} \mathrm{mL}^{-1}$ was validated using a simple model weighted by $1 / \mathrm{X}^{2}$. For BPS-G, calibration curves with concentrations ranging from 10 to $50000 \mathrm{ng} \mathrm{mL}^{-1}$ was validated using a quadratic model weighted by $1 / \mathrm{X}^{2}$. 
Due to the very wide range of concentrations required for TK studies, both the ULOQ and dilution were assessed by injecting 6 standard samples at 5000 and $50000 \mathrm{ng} \mathrm{mL}^{-1}$ for BPS and BPS-G, respectively, and 6 QC samples out of the concentration range diluted two fold and tenfold. The accuracies of all the concentrations, for both BPS and BPS-G, ranged from 84\% to $103 \%$ with CV precision lower than $13 \%$. These results fulfilled the acceptability criteria designated in the EMA guidelines as suitable for TK investigations [27].

\subsubsection{Sensitivity}

In blank plasma, a residual peak was systematically observed for BPS, likely due to BPS contamination during plasma collection, sample processing or owing to the presence of BPS in the LC system $[31,35]$. Therefore, the LOB was first evaluated. The residual BPS concentration found in blank plasma was $0.5 \pm 0.5 \mathrm{ng} \mathrm{mL}^{-1}$. The mean concentration calculated after injection of 6 samples at $1 \mathrm{ng} \mathrm{mL} L^{-1}$, was $1.2 \pm 0.7 \mathrm{ng} \mathrm{mL}^{-1}$. This concentration was different from LOB and was designated LOD. No BPS-G peak was detected in the blank plasma samples at the BPS-G retention time. According to the $\mathrm{S} / \mathrm{N}=3$ principle, the estimated LOD was close to 1 $\mathrm{ng} \mathrm{mL} \mathrm{m}^{-1}$. After 6 injections of BPS-G at $1 \mathrm{ng} \mathrm{mL}^{-1}$, the mean concentration was $1.4 \mathrm{ng} \mathrm{mL}^{-1}$ $(\mathrm{CV} \%=39 \%)$ [27]. The LLOQs were set and validated at the lowest value of the calibration curve chosen for its relevance, with acceptable precision and accuracy, to TK investigations. According to these criteria, the LLOQs determined for BPS and BPS-G were 3 and $10 \mathrm{ng} \mathrm{mL}^{-1}$, respectively (Table 3). The BPS LLOQ was much higher than values published elsewhere [36]. Further optimizations would be necessary to increase the sensitivity of our method such as adding an isolator column between the injector and the analytical column to prevent the BPS background contamination generated by the LC-MS/MS system [35] or using dansyl derivatization to improve the ionization and elution of BPS and BPS-G [36,37]. Nevertheless, this method is not designed for human biomonitoring and its LLOQs are totally suitable for our TK investigations. 


\subsubsection{Precision and accuracy}

Intra- and inter-day precisions were systematically lower than $8 \%$ for BPS and $15 \%$ for BPS$\mathrm{G}$ and accuracy ranged from 100 to $113 \%$ for BPS and from 96 to $105 \%$ for BPS-G (Table 3). Both parameters therefore satisfied the acceptance criteria in the EMA guidelines [27].

\subsubsection{Stability}

The long-term stability of BPS and BPS-G stock solutions in $\mathrm{H}_{2} \mathrm{O} / \mathrm{AcN}(1 / 1, \mathrm{v} / \mathrm{v})$ was checked by comparing the analytical response of the stock solution stored at $4{ }^{\circ} \mathrm{C}$ with that of freshly prepared stock solutions of BPS and BPS-G. Stock solutions of BPS were found to remain stable at $4^{\circ} \mathrm{C}$ for at least one year, and those of BPS-G for at least 4 months, the variation in analytical response being lower than $5 \%$ and $1 \%$ for BPS and BPS-G, respectively. The longterm stability of BPS and BPS-G in plasma was assayed by comparing the concentrations of six plasma samples stored at $-20^{\circ} \mathrm{C}$ with those of six freshly-prepared plasma samples. The QC concentrations were within $\pm 15 \%$ of their nominal value. Plasma samples can be stored at $-20^{\circ} \mathrm{C}$ for at least 3 months as the difference between the concentrations of freshly QC and stored QC was less than $5 \%$ and $8 \%$ for BPS and BPS-G, respectively. Stability during the residence time in the autosampler at $10^{\circ} \mathrm{C}$ was evaluated by assaying BPS and BPS-G in QC samples (low, middle and high) at t0, $6 \mathrm{~h}$ and $10 \mathrm{~h}$ after extraction. The resulting QC concentrations were close to their nominal values for BPS and BPS-G $( \pm 15 \%$ and $\pm 14 \%$, respectively) for at least $10 \mathrm{~h}$. This stability means that numerous plasma samples can be assayed by batch analysis.

\subsection{Applicability of the method for toxicokinetic studies of BPS and BPS-G}

The validated method permitting the simultaneous quantification of BPS and BPS-G in ovine plasma was then applied to a TK experiment. Figure 3 shows the time course of mean plasma concentrations $( \pm$ SD) of BPS and BPS-G in ewes after an intravenous administration of BPS (5 mg kg-1 bw, Figure 3A) or BPS-G (2 mg kg-1 bw, Figure 3B). 
After an intravenous administration of BPS, BPS could be quantified up to $12 \mathrm{~h}$ with concentrations decreasing from $50 \mu \mathrm{g} \mathrm{mL}^{-1}$ to LLOQ. As shown in figure 3, BPS was rapidly metabolized into BPS-G, the levels of this latter attaining $10-20 \mu \mathrm{g} \mathrm{mL}^{-1}$ as early as two minutes post injection and a maximum concentration 15 min after injection. BPS-G could be quantified up to $48 \mathrm{~h}$ with concentrations ranging from $70 \mu \mathrm{g} \mathrm{mL}^{-1}$ to LLOQ.

After an intravenous administration of purified BPS-G, BPS-G concentrations decreased over $24 \mathrm{~h}$ from $50 \mu \mathrm{g} \mathrm{mL}^{-1}$ to LLOQ. BPS could also be detected with concentrations decreasing from $350 \mathrm{ng} \mathrm{mL}^{-1}$ at 2 min post-injection to LLOQ up to one hour after BPS-G administration (Figure 3B). BPS contamination of the BPS-G dose purified from urine was below $4.4 \%$ (see section 2.4.3). The putative contamination of the administered BPS dose was calculated by multiplying the BPS AUC last obtained after intravenous BPS-G administration by the clearance of BPS (Table 4). The estimated back-calculated amount of BPS contamination was $23.2 \mu \mathrm{g} \mathrm{kg}^{-1} \mathrm{bw}$, which corresponds to $1.94 \pm 0.26 \%$ of the BPS-G dose $\left(2 \mathrm{mg} \mathrm{kg}^{-1} \mathrm{bw}\right)$. This result is in agreement with the estimated BPS contamination in purified BPS-G, but a potential in vivo hydrolysis of BPS-G into BPS cannot be excluded.

Finally, we demonstrated the suitability of our analytical method for determining the time course of both BPS and BPS-G concentrations in plasma in the same run without resorting to enzymatic hydrolysis. This direct method offers two main advantages since it can be considered as more reliable than enzymatic hydrolysis and is also less time-consuming and definitely cheaper $[15,37]$.

The TK parameters describing the disposition of BPS-G in sheep are shown in table 4. The plasma clearance of BPS-G was 7-fold lower than that of BPS, and the BPS-G half-life was consistently 1.5-fold higher. BPS was extensively conjugated into BPS-G after BPS administration, with glucuronoconjugation of $75 \pm 4 \%$ over $72 \mathrm{~h}$, a value in agreement with the mean percentage conjugation of BPS (97\%) measured in human urine [38]. Moreover, in vitro 
metabolism studies showed that the BPS glucuronoconjugate was the main metabolite in the HepaRG cell line [12].

In adult sheep, BPS (like BPA) was rapidly and mainly metabolized into its glucuronide form, which is devoid of estrogenic activity $[13,39,40]$. The volumes of distribution of BPS and BPS$\mathrm{G}\left(0.17\right.$ and $0.13 \mathrm{~L} \mathrm{~kg}^{-1}$, respectively) were of the same order of magnitude as the extravascular volume $\left(0.245 \mathrm{~L} \mathrm{~kg}^{-1}[41]\right)$, suggesting that their distribution in tissues would be limited to the interstitial space. The lower steady state distribution volumes, compared to those of BPA (tenfold for BPS) and BPA-G (three-fold for BPS-G), were consistent with their lower lipophilicities.

Furthermore, the BPS and BPS-G plasma clearances are respectively about 2-fold and 4-fold lower than those of BPA and BPA-G $[18,40]$, suggesting that the capacity to eliminate BPS is less than for BPA. Even though BPS is a structural analog of BPA, it clearly displays a different disposition within the organism, which highlights the importance of BPS and BPS-G TK investigations.

\section{Conclusion}

The present paper describes a novel on-line SPE-UPLC-MS/MS method for the simultaneous quantification of BPS and BPS-G in plasma. This method, validated according to the EMA guidelines, proved to be especially suitable for TK studies. Therefore, the first TK parameters of BPS and BPS-G were estimated and compared with TK parameters of BPA.The main advantage of this method is its ability to rapidly quantify both BPS and BPS-G, within 4.5 min, which allows the analysis of 200 samples per day including sample preparation. 
The authors thank the French National Research Program for Environmental and Occupational Health of Anses for funding this project [grant number 2015/1/112, 2015] and C. Lacassagne and N. Deschamps for their assistance and involvement in animal care.

Funding sources

This work was supported by the French National Research Program for Environmental and Occupational Health of Anses [grant number 2015/1/112, 2015]. 
References

[1] ANSES, Environmental and Occupational Health \& Safety on the Assessment of the Risks Associated with Bisphenol a for Human Health, and on Toxicological Data and Data on the Use of Bisphenols S, F, M, B, AP, AF and BADGE, OPINION of the French Agency for Food, 2013 available at:, (2013). https://www.anses.fr/fr/system/files/CHIM2009sa0331Ra-1.pdf (accessed July 19, 2016).

[2] United States Environmental Protection Agency, Bisphenol A alternatives in thermal paper, (2014). $\quad$ https://www.epa.gov/sites/production/files/201405/documents/bpa_final.pdf (accessed January 26, 2017).

[3] S.S. Andra, P. Charisiadis, M. Arora, J.V. van Vliet-Ostaptchouk, K.C. Makris, Biomonitoring of human exposures to chlorinated derivatives and structural analogs of bisphenol A, Environ. Int. 85 (2015) 352-379. doi:10.1016/j.envint.2015.09.011.

[4] C. Liao, K. Kannan, Concentrations and Profiles of Bisphenol A and Other Bisphenol Analogues in Foodstuffs from the United States and Their Implications for Human Exposure, J. Agric. Food Chem. 61 (2013) 4655-4662. doi:10.1021/jf400445n.

[5] H. Gallart-Ayala, E. Moyano, M.T. Galceran, Analysis of bisphenols in soft drinks by online solid phase extraction fast liquid chromatography-tandem mass spectrometry, Anal. Chim. Acta. 683 (2011) 227-233. doi:10.1016/j.aca.2010.10.034.

[6] J. Regueiro, T. Wenzl, Development and validation of a stable-isotope dilution liquid chromatography-tandem mass spectrometry method for the determination of bisphenols in ready-made meals, J. Chromatogr. A. 1414 (2015) 110-121. doi:10.1016/j.chroma.2015.08.037.

[7] C. Liao, K. Kannan, A Survey of Alkylphenols, Bisphenols, and Triclosan in Personal Care Products from China and the United States, Arch. Environ. Contam. Toxicol. 67 (2014) 50-59. doi:10.1007/s00244-014-0016-8.

[8] C. Liao, F. Liu, K. Kannan, Bisphenol S, a New Bisphenol Analogue, in Paper Products and Currency Bills and Its Association with Bisphenol A Residues, Environ. Sci. Technol. 46 (2012) 6515-6522. doi:10.1021/es300876n.

[9] C. Liao, K. Kannan, A survey of bisphenol A and other bisphenol analogues in foodstuffs from nine cities in China, Food Addit. Contam. Part A. 31 (2014) 319-329. doi:10.1080/19440049.2013.868611.

[10] C. Liao, F. Liu, Y. Guo, H.-B. Moon, H. Nakata, Q. Wu, K. Kannan, Occurrence of Eight Bisphenol Analogues in Indoor Dust from the United States and Several Asian Countries: Implications for Human Exposure, Environ. Sci. Technol. 46 (2012) 9138-9145. doi:10.1021/es302004w.

[11] K.A. Thayer, K.W. Taylor, S. Garantziotis, S.H. Schurman, G.E. Kissling, D. Hunt, B. Herbert, R. Church, R. Jankowich, M.I. Churchwell, R.C. Scheri, L.S. Birnbaum, J.R. Bucher, Bisphenol A, Bisphenol S, and 4-Hydroxyphenyl 4-Isoprooxyphenylsulfone (BPSIP) in Urine and Blood of Cashiers, Environ. Health Perspect. 124 (2016) 437-444. doi:10.1289/ehp.1409427.

[12] V. Le Fol, S. Aït-Aïssa, N. Cabaton, L. Dolo, M. Grimaldi, P. Balaguer, E. Perdu, L. Debrauwer, F. Brion, D. Zalko, Cell-Specific Biotransformation of Benzophenone-2 and Bisphenol-S in Zebrafish and Human in Vitro Models Used for Toxicity and Estrogenicity Screening, Environ. Sci. Technol. 49 (2015) 3860-3868. doi:10.1021/es505302c.

[13] D. Gramec Skledar, L. Peterlin Mašič, Bisphenol A and its analogs: Do their metabolites have endocrine activity?, Environ. Toxicol. Pharmacol. 47 (2016) 182-199. doi:10.1016/j.etap.2016.09.014.

[14] X. Ye, L.-Y. Wong, J. Kramer, X. Zhou, T. Jia, A.M. Calafat, Urinary Concentrations of Bisphenol A and Three Other Bisphenols in Convenience Samples of U.S. Adults during 
2000-2014, Environ. Sci. Technol. $49 \quad$ (2015) 11834-11839. doi:10.1021/acs.est.5b02135.

[15] C. Liao, F. Liu, H. Alomirah, V.D. Loi, M.A. Mohd, H.-B. Moon, H. Nakata, K. Kannan, Bisphenol S in Urine from the United States and Seven Asian Countries: Occurrence and Human Exposures, Environ. Sci. Technol. 46 (2012) 6860-6866. doi:10.1021/es301334j.

[16] D. Chen, K. Kannan, H. Tan, Z. Zheng, Y.-L. Feng, Y. Wu, M. Widelka, Bisphenol Analogues Other Than BPA: Environmental Occurrence, Human Exposure, and Toxicity-A Review, Environ. Sci. Technol. 50 (2016) 5438-5453. doi:10.1021/acs.est.5b05387.

[17] J.R. Rochester, A.L. Bolden, Bisphenol S and F: A Systematic Review and Comparison of the Hormonal Activity of Bisphenol A Substitutes, Environ. Health Perspect. 123 (2015) 643-650. doi:10.1289/ehp.1408989.

[18] G. Gauderat, N. Picard-Hagen, P.-L. Toutain, T. Corbel, C. Viguié, S. Puel, M.Z. Lacroix, P. Mindeguia, A. Bousquet-Melou, V. Gayrard, Bisphenol A glucuronide deconjugation is a determining factor of fetal exposure to bisphenol A, Environ. Int. 86 (2016) 52-59. doi:10.1016/j.envint.2015.10.006.

[19] M.Z. Lacroix, S. Puel, S.H. Collet, T. Corbel, N. Picard-Hagen, P. Toutain, C. Viguié, V. Gayrard, Simultaneous quantification of bisphenol A and its glucuronide metabolite (BPA-G) in plasma and urine: Applicability to toxicokinetic investigations, Talanta. 85 (2011) 2053-2059. doi:10.1016/j.talanta.2011.07.040.

[20] N. Caballero-Casero, L. Lunar, S. Rubio, Analytical methods for the determination of mixtures of bisphenols and derivatives in human and environmental exposure sources and biological fluids. A review, Anal. Chim. Acta. 908 (2016) 22-53. doi:10.1016/j.aca.2015.12.034.

[21] L. Lu, Y. Yang, J. Zhang, B. Shao, Determination of seven bisphenol analogues in reed and Callitrichaceae by ultra performance liquid chromatography-tandem mass $\begin{array}{llllll}\text { spectrometry, J. } & \text { Chromatogr. } & \text { B. 95-85. }\end{array}$ doi:10.1016/j.jchromb.2014.02.003.

[22] Y. Yang, L. Lu, J. Zhang, Y. Yang, Y. Wu, B. Shao, Simultaneous determination of seven bisphenols in environmental water and solid samples by liquid chromatographyelectrospray tandem mass spectrometry, J. Chromatogr. A. 1328 (2014) 26-34. doi:10.1016/j.chroma.2013.12.074.

[23] J. Regueiro, T. Wenzl, Determination of bisphenols in beverages by mixed-mode solidphase extraction and liquid chromatography coupled to tandem mass spectrometry, J. Chromatogr. A. 1422 (2015) 230-238. doi:10.1016/j.chroma.2015.10.046.

[24] Y. Yang, J. Guan, J. Yin, B. Shao, H. Li, Urinary levels of bisphenol analogues in residents living near a manufacturing plant in south China, Chemosphere. 112 (2014) 481-486. doi:10.1016/j.chemosphere.2014.05.004.

[25] J. Liu, J. Li, Y. Wu, Y. Zhao, F. Luo, S. Li, L. Yang, E.K. Moez, I. Dinu, J.W. Martin, Bisphenol A Metabolites and Bisphenol S in Paired Maternal and Cord Serum, Environ. Sci. Technol. 51 (2017) 2456-2463. doi:10.1021/acs.est.6b05718.

[26] S.S. Andra, C. Austin, J. Yang, D. Patel, M. Arora, Recent advances in simultaneous analysis of bisphenol $\mathrm{A}$ and its conjugates in human matrices: Exposure biomarker $\begin{array}{llllll}\text { perspectives, } & \text { Sci. } & \text { Total } & \text { Environ. } & 572 & \text { (2016) }\end{array}$ doi:10.1016/j.scitotenv.2016.07.062.

[27] European Medicines Agency - Guideline on bioanalytical method validation, (n.d.). http://www.ema.europa.eu/docs/en_GB/document_library/Scientific_guideline/2011/08/ WC500109686.pdf (accessed March 23, 2017).

[28] M. Gibaldi, D. Perrier, Pharmacoinetics. 2nd ed. Marcel Dekker, New York, NY., 1982. 
[29] M.O. Karlsson, L.B. Sheiner, Estimating bioavailability when clearance varies with time, Clin. Pharmacol. Ther. 55 (1994) 623-637. doi:10.1038/clpt.1994.79.

[30] P.L. Toutain, A. Bousquet-Mélou, Bioavailability and its assessment, J. Vet. Pharmacol. Ther. 27 (2004) 455-466. doi:10.1111/j.1365-2885.2004.00604.x.

[31] N. Gatimel, M.Z. Lacroix, S. Chanthavisouk, N. Picard-Hagen, V. Gayrard, J. Parinaud, R.D. Léandri, Bisphenol A in culture media and plastic consumables used for ART, Hum. Reprod. 31 (2016) 1436-1444. doi:10.1093/humrep/dew116.

[32] X. Ye, Z. Kuklenyik, L.L. Needham, A.M. Calafat, Automated On-Line ColumnSwitching HPLC-MS/MS Method with Peak Focusing for the Determination of Nine Environmental Phenols in Urine, Anal. Chem. 77 (2005) 5407-5413. doi:10.1021/ac050390d.

[33] A. Cariot, A. Dupuis, M. Albouy-Llaty, B. Legube, S. Rabouan, V. Migeot, Reliable quantification of bisphenol $\mathrm{A}$ and its chlorinated derivatives in human breast milk using UPLC-MS/MS method, Talanta. 100 (2012) 175-182. doi:10.1016/j.talanta.2012.08.034.

[34] H. Zhao, L. Xiang, J. Li, Z. Yang, J. Fang, C. Zhao, S. Xu, Z. Cai, Investigation on fragmentation pathways of bisphenols by using electrospray ionization Orbitrap mass spectrometry, Rapid Commun. Mass Spectrom. 30 (2016) 1901-1913.

[35] Y. Niu, J. Zhang, Y. Wu, B. Shao, Simultaneous determination of bisphenol A and alkylphenol in plant oil by gel permeation chromatography and isotopic dilution liquid chromatography-tandem mass spectrometry, J. Chromatogr. A. 1218 (2011) 5248-5253. doi:10.1016/j.chroma.2011.06.005.

[36] J. Liu, J. Li, Y. Wu, Y. Zhao, F. Luo, S. Li, L. Yang, E.K. Moez, I.A. Dinu, J.W. Martin, Bisphenol A Metabolites and Bisphenol S in Paired Maternal and Cord Serum, Environ. Sci. Technol. (2017). doi:10.1021/acs.est.6b05718.

[37] B.A. Rocha, B.R.B. da Costa, N.C.P. de Albuquerque, A.R.M. de Oliveira, J.M.O. Souza, M. Al-Tameemi, A.D. Campiglia, F. Barbosa Jr., A fast method for bisphenol A and six analogues (S, F, Z, P, AF, AP) determination in urine samples based on dispersive liquidliquid microextraction and liquid chromatography-tandem mass spectrometry, Talanta. 154 (2016) 511-519. doi:10.1016/j.talanta.2016.03.098.

[38] X. Zhou, J.P. Kramer, A.M. Calafat, X. Ye, Automated on-line column-switching high performance liquid chromatography isotope dilution tandem mass spectrometry method for the quantification of bisphenol $\mathrm{A}$, bisphenol $\mathrm{F}$, bisphenol $\mathrm{S}$, and 11 other phenols in urine, J. Chromatogr. B. 944 (2014) 152-156. doi:10.1016/j.jchromb.2013.11.009.

[39] D.G. Skledar, J. Schmidt, A. Fic, I. Klopčič, J. Trontelj, M.S. Dolenc, M. Finel, L.P. Mašič, Influence of metabolism on endocrine activities of bisphenol S, Chemosphere. 157 (2016) 152-159. doi:10.1016/j.chemosphere.2016.05.027.

[40] S.H. Collet, N. Picard-Hagen, M.Z. Lacroix, S. Puel, C. Viguié, A. Bousquet-Melou, P.L. Toutain, V. Gayrard, Allometric scaling for predicting human clearance of bisphenol A, Toxicol. Appl. Pharmacol. 284 (2015) 323-329. doi:10.1016/j.taap.2015.02.024.

[41] J.P. Coghlan, J.S. Fan, B.A. Scoggins, A.A. Shulkes, Measurement of extracellular fluid volume and blood volume in sheep, Aust. J. Biol. Sci. 30 (1977) 71-84. doi:10.1071/BI9770071. 
Figure captions:

Figure 1: Chromatograms obtained after acetonitrile precipitation of plasma containing BPA and BPA-G (A), BPS and BPS-G (B) at $100 \mathrm{ng} \mathrm{mL}^{-1}$ following by elution on BEH C18 column [19]. These conditions do not allow the detection of BPS-G. BPS is very poorly eluted with a split peak.

Figure 2: Comparison of two chromatograms of low QC samples of BPS and BPS-G (9 and 30 ng $\mathrm{mL}^{-1}$, respectively): (A) BPS $(\mathrm{RT}=3.04 \mathrm{~min})$ and $\mathrm{BPS}-\mathrm{G}(\mathrm{RT}=2.55 \mathrm{~min})$ analyzed by SPEUPLC-MS/MS and (B) BPS (RT = $2.73 \mathrm{~min})$ and BPS-G $(\mathrm{RT}=0.76 \mathrm{~min})$ analyzed by UPLCMS/MS.

Figure 3: Mean \pm SD of plasma concentrations of BPS (०) and BPS-G ( $\mathbf{a})$ versus time after an intravenous administration of BPS $\left(5 \mathrm{mg} \mathrm{kg}^{-1} \mathrm{bw}\right)(\mathrm{A})$ or after an intravenous administration of BPS-G (2 mg kg-1 bw) (B) in four sheep. The profile of BPS concentrations observed after the BPS-G intravenous administration (B) could be due to contamination (1.94\%) of the BPS-G dose purified from sheep urine. 
Table 1: BPS and BPS-G molecular properties and mass data.

\begin{tabular}{|c|c|c|c|c|c|c|}
\hline Molecule & $\begin{array}{l}\text { Molar } \\
\text { weight }\end{array}$ & $\begin{array}{l}\text { Retention } \\
\text { time } \\
\text { (min) }\end{array}$ & $\begin{array}{l}\text { Parent } \\
\text { ions }\end{array}$ & $\begin{array}{l}\text { Daughter } \\
\text { ions }\end{array}$ & $\begin{array}{l}\text { Cone } \\
\text { voltage } \\
\text { (V) }\end{array}$ & $\begin{array}{l}\text { Ecoll } \\
(\mathrm{eV})\end{array}$ \\
\hline \multirow[t]{2}{*}{ BPS } & 250 & 3.04 & 249.10 & 92 & 42 & 33 \\
\hline & & & & $108^{*}$ & & 26 \\
\hline \multirow[t]{2}{*}{ BPSd8 } & 258 & 3.07 & 257.10 & 95 & 40 & 34 \\
\hline & & & & $112 *$ & & 28 \\
\hline \multirow[t]{2}{*}{ BPS-G } & 426 & 2.55 & 425.16 & 108 & 26 & 46 \\
\hline & & & & $249 *$ & & 28 \\
\hline \multirow[t]{2}{*}{ BPS-Gd8 } & 434 & 2.55 & 433.16 & 112 & 26 & 56 \\
\hline & & & & $257 *$ & & 28 \\
\hline
\end{tabular}

* MRM transition used for quantification 
Table 2: Contribution of the on-line SPE system to method performances.

\begin{tabular}{|c|c|c|c|}
\hline Parameters & Mode of evaluation & Mean QC BPS (\%) & Mean QC BPS-G (\%) \\
\hline $\begin{array}{l}\text { Recovery without on-line } \\
\text { SPE }\end{array}$ & $\begin{array}{l}\text { plasma with } \mathrm{PP} / \mathrm{H}_{2} \mathrm{O} \\
\text { without PP }\end{array}$ & 108 & 2 \\
\hline $\begin{array}{l}\text { Matrix effect without on- } \\
\text { line SPE }\end{array}$ & $\begin{array}{l}\text { plasma with } \mathrm{PP} / \mathrm{H}_{2} \mathrm{O} \text { with } \\
\text { PP }\end{array}$ & 106 & 4 \\
\hline $\begin{array}{l}\text { Matrix effect with on-line } \\
\text { SPE }\end{array}$ & $\begin{array}{l}\text { On-line SPE plasma with } \\
\text { PP/ On-line SPE } \mathrm{H}_{2} \mathrm{O} \text { with } \\
\text { PP }\end{array}$ & 45 & 71 \\
\hline $\begin{array}{l}\text { Global recovery }(\mathrm{SPE}+\mathrm{PP}+ \\
\text { matrix effect) }\end{array}$ & $\begin{array}{l}\text { On-line SPE plasma with } \\
\mathrm{PP} / \mathrm{H}_{2} \mathrm{O} \text { without } \mathrm{PP}\end{array}$ & 31 & 106 \\
\hline $\begin{array}{l}\text { Sensitivity gain without vs } \\
\text { with on-line SPE }\end{array}$ & $\begin{array}{l}\text { On-line SPE plasma with } \\
\text { PP /plasma with PP }\end{array}$ & 29 & 5600 \\
\hline
\end{tabular}


Table 3: Validation results of BPS and BPS-G in sheep plasma

\begin{tabular}{|c|c|c|c|c|c|c|c|c|c|}
\hline \multirow{2}{*}{$\begin{array}{l}\text { BPS nominal } \\
\text { concentration } \\
\left(\mathrm{ng} \mathrm{mL} \mathrm{mL}^{-1}\right)\end{array}$} & \multirow{2}{*}{$\begin{array}{c}\text { Mean } \\
\left(\mathrm{ng} \mathrm{mL}^{-1}\right)\end{array}$} & \multirow{2}{*}{$\begin{array}{c}\text { Accuracy } \\
(\%)\end{array}$} & \multicolumn{2}{|c|}{ Precision CV (\%) } & \multirow{2}{*}{$\begin{array}{l}\text { BPS-G nominal } \\
\text { concentration } \\
\left(\mathrm{ng} \mathrm{mL}^{-1}\right)\end{array}$} & \multirow{2}{*}{$\begin{array}{c}\text { Mean } \\
\left(\mathrm{ng} \mathrm{mL}^{-1}\right)\end{array}$} & \multirow{2}{*}{ Accuracy } & \multicolumn{2}{|c|}{ Precision CV (\%) } \\
\hline & & & Intra-day & Inter-day & & & & Intra-day & Inter-day \\
\hline LLOQ $3(n=18)$ & 2.79 & 93 & 13 & 13 & LLOQ $10(n=6)$ & 8.4 & 84 & 14 & - \\
\hline ULOQ $5000(n=6)$ & 4348 & 87 & 13 & - & ULOQ $50000(n=6)$ & 51500 & 103 & 10 & - \\
\hline Dilution $(n=6)$ & & & & & Dilution $(n=6)$ & & & & \\
\hline $1 / 24000$ & 3354 & 84 & 3 & - & $1 / 240000$ & 38548 & 96 & 3 & - \\
\hline $1 / 10800$ & 727 & 91 & 3 & - & $1 / 108000$ & 8047 & 101 & 4 & - \\
\hline $\mathrm{QC}(\mathrm{n}=18)$ & & & & & $\mathrm{QC}(\mathrm{n}=18)$ & & & & \\
\hline 9 & 10.2 & 113 & 8 & 8 & 30 & 31 & 105 & 11 & 15 \\
\hline 250 & 264 & 106 & 3 & 6 & 2500 & 2411 & 96 & 3 & 7 \\
\hline 3750 & 3734 & 100 & 6 & 9 & 37500 & 36264 & 97 & 6 & 7 \\
\hline
\end{tabular}


Table 4: Mean ( \pm SD) toxicokinetic parameters of BPS and BPS-G, BPA and BPA-G [18] from sheep after an iv administration. (Cl: plasma clearance, Vss: Volume of distribution at steady state, MRT: Mean residence time, t1/2: half-life).

\begin{tabular}{lcrrr}
\hline $\begin{array}{l}\text { Toxicokinetic } \\
\text { parameters }\end{array}$ & $\begin{array}{c}\text { BPS } \\
(\mathrm{n}=4)\end{array}$ & $\begin{array}{c}\text { BPS-G } \\
(\mathrm{n}=4)\end{array}$ & \multicolumn{1}{c}{$\begin{array}{c}\text { BPA } \\
(\mathrm{n}=8)\end{array}$} & \multicolumn{1}{c}{$\begin{array}{c}\text { BPAG } \\
(\mathrm{n}=7)\end{array}$} \\
\hline $\mathrm{Cl}(\mathrm{L} / \mathrm{kg} . \mathrm{h}))$ & $0.57 \pm 0.13$ & $0.08 \pm 0.02$ & 1.75 & 0.33 \\
Vss $(\mathrm{L} / \mathrm{kg})$ & $0.17 \pm 0.04$ & $0.13 \pm 0.03$ & 1.28 & 0.32 \\
$\mathrm{MRT}(\mathrm{h})$ & $0.30 \pm 0.04$ & $1.7 \pm 0.4$ & 0.75 & 0.84 \\
$\mathrm{t}_{1 / 2}(\mathrm{~h})$ & $1.80 \pm 0.44$ & $2.8 \pm 0.6$ & 1.6 & 3.2 \\
\hline
\end{tabular}




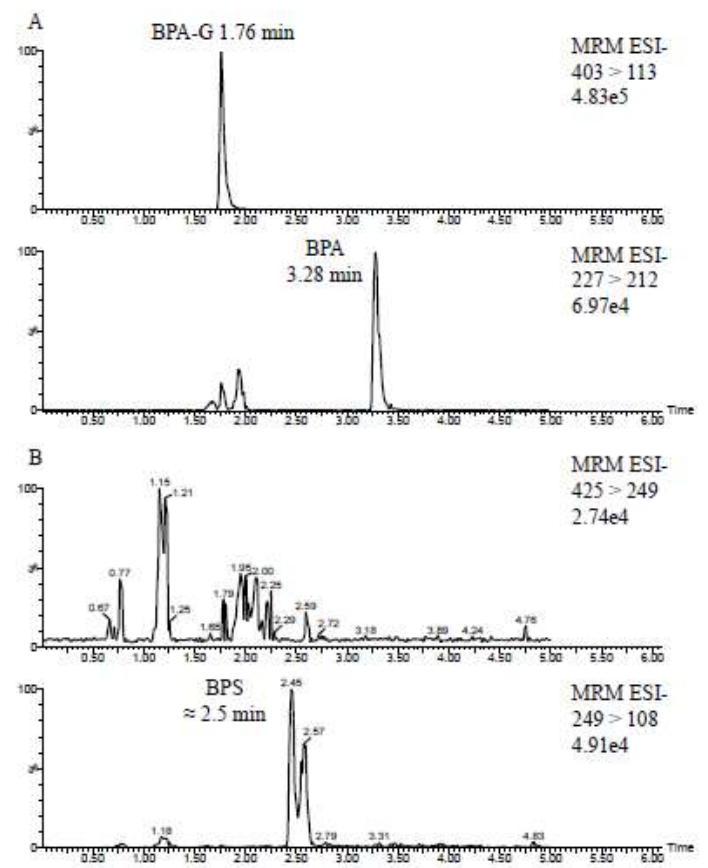

Comment citer ce document

Grandin, F., Picard-Hagen, N., Gayrard, V., Puel, S., Viguié, C., Toutain, P.-L., Debrauwer, L., Lacroix, M. Z. (Auteur de correspondance) (2017). Development of an on-line solid phase extraction ultra performance liquid chromatography technique coupled to tandem mass spectrometry for 


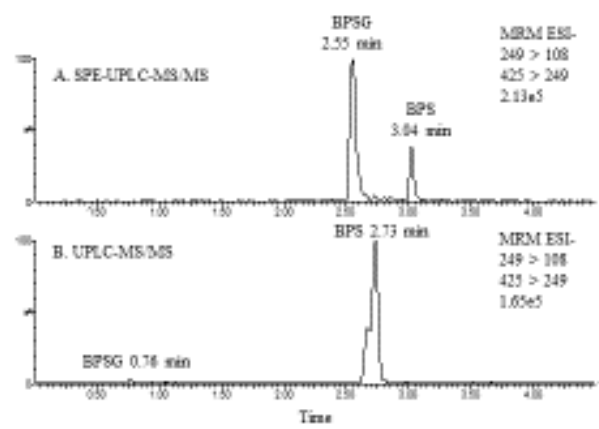

\section{8}

Comment citer ce document:

Grandin, F., Picard-Hagen, N., Gayrard, V., Puel, S., Viguié, C., Toutain, P.-L., Debrauwer, L., Lacroix, M. Z. (Auteur de correspondance) (2017). Development of an on-line solid phase extraction ultra performance liquid chromatography technique coupled to tandem mass spectrometry for 


\section{A}
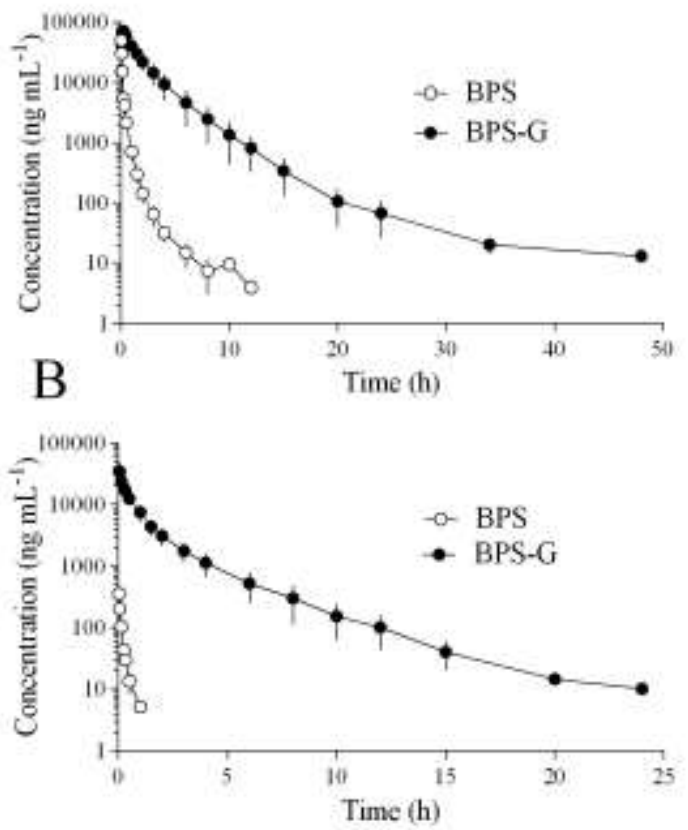

Comment citer ce document:

Grandin, F., Picard-Hagen, N., Gayrard, V., Puel, S., Viguié, C., Toutain, P.-L., Debrauwer, L., Lacroix, M. Z. (Auteur de correspondance) (2017). Development of an on-line solid phase extraction ultra performance liquid chromatography technique coupled to tandem mass spectrometry for 